\title{
Protective Effects of Dioscorea batatas Flesh and Peel Extracts against Ethanol-Induced Gastric Ulcer in Mice
}

\author{
Siyul Byeon ${ }^{1,+}$, Jisun Oh ${ }^{1,+}$, Ji Sun Lim ${ }^{1}$, Jeong Soon Lee ${ }^{2}$ and Jong-Sang Kim ${ }^{1, * \mathbb{D}}$ \\ 1 School of Food Science and Biotechnology, Kyungpook National University, Daegu 41566, Korea; \\ sy1_6@naver.com (S.B.); j.oh@knu.ac.kr (J.O.); lzsunny@hanmail.net (J.S.L.) \\ 2 Forest Resources Development Institute of Gyeongsangbuk-do, Andong 36605, Korea; ljs7942@korea.kr \\ * Correspondence: vision@knu.ac.kr; Tel.: +82-53-950-5752; Fax: +82-53-950-6750 \\ + These authors contributed equally to this work.
}

Received: 7 October 2018; Accepted: 2 November 2018; Published: 5 November 2018

\begin{abstract}
Gastric ulcer is a major digestive disorder and provoked by multifactorial etiologies, including excessive alcohol consumption. In this study, we examined the gastroprotective effect of aqueous and ethanolic extracts of Dioscorea batatas Decne (DBD; commonly called Chinese yam) flesh or peel against acidified ethanol-induced acute gastric damage in mice. Our findings demonstrated that oral supplementation of aqueous or ethanolic extracts of DBD flesh or peel before ulcer induction was significantly effective in macroscopically and histologically alleviating ethanol-induced pathological lesions in gastric mucosa, decreasing the plasma levels of inflammatory mediators, such as nitric oxide and interleukin-6, attenuating the gastric expression of cyclooxygenase-2, and increasing the gastric content of prostaglandin $\mathrm{E}_{2}$. In particular, pretreatment with the flesh extract prepared in $60 \%$ ethanol prominently decreased the expression of biomarkers of oxidative stress, including the plasma levels of 8-hydroxy-2-guanosine and malondialdehyde, and restored heme oxygenase- 1 expression and superoxide dismutase activity in the stomach. Overall, these findings suggest that the oral supplementation with DBD extract, especially flesh ethanol extract, prior to excessive alcohol consumption, may exert a protective effect against ethanol-induced gastric mucosal damage in vivo, presumably through the activation of the antioxidant system and suppression of the inflammatory response.
\end{abstract}

Keywords: Dioscorea batatas Decne; ethanol-induced damage; gastric ulcer; inflammation; antioxidant

\section{Introduction}

Gastric ulcers are provoked by multifactorial etiologies, such as Helicobacter pylori infection, stress, smoking, excessive intake of non-steroidal anti-inflammatory drugs, and excessive alcohol consumption [1-3].

In particular, ethanol is a damaging agent that causes an acute inflammatory response accompanied by oxidative damage of the cellular components in the gastric wall $[4,5]$. The damaged region usually exhibits upregulated expression of nuclear factor kappa-light-chain-enhancer of activated $B$ cells $(\mathrm{NF}-\mathrm{kB})$, the master regulator of inflammatory responses, and its downstream enzyme cyclooxygenase-2 (COX-2) [6]. In addition, nitric oxide (NO) production is enhanced through the activation of inducible NO synthase (iNOS). The release of proinflammatory cytokines, such as tumor necrosis factor $\alpha(\mathrm{TNF} \alpha)$ and interleukin-6 (IL-6), has been associated with the recruitment of macrophages and neutrophils, subsequently leading to gastric inflammation [7].

Extensive research has been carried out to identify the protective potentials of diverse herbs, vegetables, and plants against gastric ulcers [8-10]. Numerous plants, or their phytoconstituents, 
have been found to be effective in relieving the morphological and histological features of gastric ulcerative lesions by increasing the biosynthesis of gastric prostaglandin and downregulating the expression of proinflammatory enzymes. The dietary plant extracts or their components with strong antioxidant activity may exert anti-inflammatory activity via crosstalk between the NF- $\mathrm{kB}$-mediated inflammatory pathway and nuclear factor E2-related factor 2 (Nrf2)-mediated antioxidant defense signaling pathway [11-13]. These observations are suggestive of the in vivo protective effects of edible plants against inflammatory response and oxidative stress.

Dioscorea batatas Decne (DBD; a synonym for Dioscorea polystachya Turcz.), commonly called Chinese yam, has been used as a traditional medicine owing to its several biologically beneficial effects [14-16]. Previous studies have demonstrated that Chinese yam exerts strong antioxidative capacity (effectively removing free radicals), and in vitro anti-inflammatory activity (downregulating inflammatory factors) $[14,16,17]$. In particular, dioscin isolated from Dioscorea nipponica was shown to have a protective effect against ethanol-induced liver injury through the reduction of oxidative stress, inflammatory cytokine production, apoptosis, and liver steatosis [18].

In the present study, we evaluated the in vivo gastroprotective effects of aqueous and ethanolic extracts of the flesh or peel of Chinese yam and investigated underlying mechanisms in an ethanol-induced gastric ulcer mouse model.

\section{Materials and Methods}

\subsection{Preparation of Chinese Yam Extracts}

Dry-powdered DBD flesh and peel were obtained from the Forest Resources Development Institute of Gyeongsangbuk-do (Andong, Korea). The flesh or peel powder was extracted in distilled water (DW) or aqueous ethanolic solution $(60 \%$ or $95 \%(v / v)$ ethanol in DW), as previously described [19]. The extracts were filtered through filter papers $(8 \mu \mathrm{m}$ pore size, Whatman, Little Chalfont, UK), vacuum-evaporated (EYELA N-1000, Tokyo, Japan), and subsequently freeze-dried. The lyophilized extracts were dissolved in ethanol for further examinations.

\subsection{Development of Ethanol-Induced Gastric Ulcer}

Animal study was approved and conducted by the guidelines of the Institutional Animal Care and Use Committee of the Kyungpook National University (approval number: KNU 2017-151). Six-week-old male Institute of Cancer Research (ICR) mice were purchased from Daehan BioLink (Eumseong, Korea). The experimental animals were maintained under controlled laboratory conditions (temperature of $25^{\circ} \mathrm{C}$, humidity $50 \pm 5 \%, 12 \mathrm{~h}$ light/dark cycle). Mice were allowed ad libitum access to drinking water and chow (AIN-76A based cereal feed, Chunhajeil Feed Co., Daejeon, Korea).

After 1 week acclimation, mice weighing $34 \pm 2 \mathrm{~g}$ were restricted from access to food for $24 \mathrm{~h}$ prior to the administration of the water extract (WE) or ethanol extract (EE; extracts in $60 \%$ and $95 \%$ ethanol were referred to as EE-60 and EE-95, respectively). Each extract was dissolved in vehicle, composed of $5 \%(v / v)$ Tween-80, 10\% $(v / v)$ polyethylene glycol, $10 \%(v / v)$ dimethyl sulfoxide (DMSO), and 10\% ethanol in saline, and orally administered at a single dose of either 100 or $200 \mathrm{mg} / \mathrm{kg}$ body weight (BW).

A total of 120 mice were randomized into 15 groups (8 mice per group; Table 1) as follows; group 1 received saline (no ulceration) and vehicle (no treatment), group 2 received acidified ethanol (60\% ethanol in saline containing $150 \mathrm{mM} \mathrm{HCl} ; 200 \mu \mathrm{L} /$ mouse) and the vehicle, group 3 received acidified ethanol and omeprazole (Sigma Aldrich, St. Louis, MO, USA; $20 \mathrm{mg} / \mathrm{kg} \mathrm{BW}$ ), group 4 received acidified ethanol and flesh WE at $100 \mathrm{mg} / \mathrm{kg}$ BW, group 5 received acidified ethanol and flesh WE at $200 \mathrm{mg} / \mathrm{kg} \mathrm{BW}$, group 6 received acidified ethanol and flesh EE-60 at $100 \mathrm{mg} / \mathrm{kg} \mathrm{BW}$, group 7 received acidified ethanol and flesh EE-60 at $200 \mathrm{mg} / \mathrm{kg}$ BW, group 8 received acidified ethanol and flesh EE-95 at $100 \mathrm{mg} / \mathrm{kg} \mathrm{BW}$, group 9 received acidified ethanol and flesh EE-95 at $200 \mathrm{mg} / \mathrm{kg} \mathrm{BW}$, group 10 received acidified ethanol and peel WE at $100 \mathrm{mg} / \mathrm{kg} B W$, group 11 received acidified ethanol and 
peel WE at $200 \mathrm{mg} / \mathrm{kg} \mathrm{BW}$, group 12 received acidified ethanol and peel EE-60 at $100 \mathrm{mg} / \mathrm{kg}$ BW, group 13 received acidified ethanol and peel EE-60 at $200 \mathrm{mg} / \mathrm{kg}$ BW, group 14 received acidified ethanol and peel EE-95 at $100 \mathrm{mg} / \mathrm{kg}$ BW, and group 15 received acidified ethanol and peel EE-95 at $200 \mathrm{mg} / \mathrm{kg}$ BW.

Table 1. Experimental groups of ICR mice.

\begin{tabular}{|c|c|c|c|c|}
\hline Group No. & \multicolumn{3}{|c|}{ Treatment ${ }^{1)}$} & $\begin{array}{c}\text { Dose } \\
(\mathrm{mg} / \mathrm{kg} \mathrm{BW})\end{array}$ \\
\hline 1 & Normal & \multicolumn{2}{|c|}{ Vehicle } & - \\
\hline 2 & & \multicolumn{2}{|c|}{ Vehicle } & - \\
\hline 3 & & \multicolumn{2}{|c|}{ OMEP $^{3)}$} & 20 \\
\hline 4 & & \multirow{6}{*}{ Flesh } & \multirow{2}{*}{$\mathrm{WE}^{4)}$} & 100 \\
\hline 5 & & & & 200 \\
\hline 6 & \multirow{10}{*}{ Ulcerated $^{2)}$} & & \multirow{2}{*}{ EE-60 5) } & 100 \\
\hline 7 & & & & 200 \\
\hline 8 & & & FF_95 6) & 100 \\
\hline 9 & & & & 200 \\
\hline 10 & & \multirow{6}{*}{ Peel } & \multirow{2}{*}{ WE } & 100 \\
\hline 11 & & & & 200 \\
\hline 12 & & & \multirow{2}{*}{ EE-60 } & 100 \\
\hline 13 & & & & 200 \\
\hline 14 & & & \multirow{2}{*}{ EE-95 } & 100 \\
\hline 15 & & & & 200 \\
\hline
\end{tabular}

1) The samples were dissolved in the vehicle (5\% $(v / v)$ Tween- $80,10 \%(v / v)$ polyethylene glycol, $10 \%(v / v)$ DMSO, and $10 \%$ ethanol in saline) and orally administered to the mice at the designated doses. ${ }^{2)}$ Gastric ulceration was induced by intragastric instillation of acidified ethanol $(60 \%$ ethanol in saline containing $150 \mathrm{mM} \mathrm{HCl}$; $200 \mu \mathrm{L} /$ mouse). ${ }^{3)}$ OMEP, omeprazole used as a positive control. ${ }^{4)} \mathrm{WE}$, water extract; the sample extracted using distilled water. ${ }^{5)}$ EE-60, ethanol extract; the sample extracted using 60\% ethanol. ${ }^{6)}$ EE-95, ethanol extract; the sample extracted using 95\% ethanol. ICR: Institute of Cancer Researc.

After $3 \mathrm{~h}$ resting, mice were subjected to gastric ulceration induction by intragastric instillation of acidified ethanol and were sacrificed after $1 \mathrm{~h}$ [20]. The blood and stomach were collected for further histological and biochemical analyses.

\subsection{Macroscopic Observation}

The removed stomach was cut open along the greater curvature, rinsed in saline, and macroscopically imaged. Gastric lesions were assessed by blinded observers, and scored as follows [21]: 0 , no lesions; 1-2, small lesions; 3-4, small ulcer; 5-6, large ulcer; 7, full of ulcers.

\subsection{Histological Analysis}

Collected stomach tissues were fixed in a 10\% $(v / v)$ formalin solution and then paraffin-embedded as previously described [22]. Paraffin blocks were sectioned at $5 \mu \mathrm{m}$ thickness using a microtome (RM-2125 RT; Leica, Nussloch, Germany). Tissue sections were stained with hematoxylin and eosin (H\&E) dyes. Tissue damage was observed under a microscope (Eclipse 80i; Nikon, Tokyo, Japan).

\subsection{Measurement of 8-Hydroxy-2'-Deoxyguanosine (8-OHdG) Level}

The plasma 8-OHdG concentration was determined using an enzyme-linked immunosorbent assay (ELISA) kit (Enzo Life Sciences, Inc., Farmingdale, NY, USA) as previously described [22]. 
Briefly, $50 \mu \mathrm{L}$ of plasma samples, or a series of standard dilutions, were dispensed into each well of an immunoassay plate. The samples were allowed to react with a primary antibody against mouse 8-OHdG and, subsequently, with a horse radish peroxidase (HRP)-conjugated anti-mouse IgG. Antibody reactivity was visualized using 3, 3', 5, 5'-tetramethylbenzidine (TMB) substrate. The absorbance was measured at $450 \mathrm{~nm}$ using a microplate reader (Sunrise ${ }^{\mathrm{TM}}$, Tecan Group Ltd., Männedorf, Switzerland).

\subsection{Determination of Malondialdehyde (MDA) Level}

The stomach tissues were homogenized in lysis buffer $(0.1 \mathrm{M}$ phosphate buffer, $\mathrm{pH} 7.4)$ and centrifuged at $10,000 \times g$ for $30 \mathrm{~min}$ at $4{ }^{\circ} \mathrm{C}$. The supernatant was used to quantify the content of thiobarbituric acid reactive substances (TBARS) using an assay kit (Cat \# ALX-850-287; Enzo Life Sciences, Inc., Farmingdale, NY, USA) according to the manufacturer's instructions. After reaction completion, the absorbance was detected at $532 \mathrm{~nm}$.

\subsection{Determination of Gastric Prostaglandin $E_{2}\left(P G E_{2}\right)$ Level}

The supernatant of stomach tissue homogenate was subjected to measurement of $\mathrm{PGE}_{2}$ level using an ELISA kit (Cat \# 514010; Cayman chemical, Ann Arbor, MI, USA). The stomach tissues were homogenized in lysis buffer $(0.1 \mathrm{M}$ phosphate, $\mathrm{pH} 7.4$, containing $1 \mathrm{mM}$ EDTA, and $10 \mu \mathrm{M}$ indomethacin) followed by centrifugation at $10,000 \times \mathrm{g}$ for $30 \mathrm{~min}$ at $4{ }^{\circ} \mathrm{C}$. The level of $\mathrm{PGE}_{2}$ in the homogenate was quantified by interpolating the absorbance values at $420 \mathrm{~nm}$ to a standard curve.

\subsection{Determination of Catalase (CAT) and Superoxide Dismutase (SOD) Activities}

The supernatant of stomach tissue homogenate was subjected to analysis using commercially available kits; CAT ELISA kit (Roche, Basel, Switzerland) and SOD assay kit (Dojindo Molecular Technologies, Inc., Rockville, MD, USA), as previously described [23,24].

\subsection{Determination of Plasma Nitric Oxide (NO) and Cytokine Levels}

The plasma NO concentration was determined by measuring the nitrite content using the Griess reagent system (Promega, Madison, WI, USA). The levels of cytokines were quantified using ELISA kits for IL-6 and TNF $\alpha$ (all from BD Biosciences, San Diego, CA, USA), as previously described [22].

\subsection{Western Blot Analysis}

Nuclear and cytoplasmic proteins in the tissue homogenate were fractionated using NE-PER ${ }^{\mathrm{TM}}$ Nuclear and Cytoplasmic Protein Extraction Kit (Thermo Fisher Scientific., Rockford, IL, USA), as previously described [22]. After quantification and denaturation, the proteins were electrophoretically separated on a sodium dodecyl sulfate polyacrylamide gels, and the separated bands were transferred onto polyvinylidene fluoride membranes (Merck Millipore Corp., Billerica, MA, USA). The primary antibodies used in this study were directed to COX-2 (Cell Signaling Technology, Danvers, MA, USA), heme oxygenase-1 (HO-1; Abcam, Cambridge, UK), or $\beta$-actin (Santa Cruz Biotechnology, Dallas, TX, USA). Appropriate secondary antibodies, HRP-conjugated, were used for each primary antibody. Protein bands were developed, digitalized, and densitometrically analyzed using Image Studio Lite version 5.2 (LI-COR Biotechnology, Lincoln, NE, USA).

\section{Statistical Analysis}

All the statistical analyses were performed using the SPSS software version 23.0 (SPSS Inc., Chicago, IL, USA). Comparisons were conducted via one-way analysis of variance (ANOVA) followed by Duncan's multiple range test. The $p$-values less than 0.05 were considered significant. Significant differences were indicated using different alphabetical letters. 


\section{Results}

\subsection{DBD Flesh and Peel Extracts Alleviated Acidified Ethanol-Induced Gastric Mucosal Damage}

To examine the gastroprotective effect of DBD flesh or peel extract (either water or ethanol) in vivo, adult male ICR mice were pretreated with the extracts $3 \mathrm{~h}$ prior to the induction of acute gastric ulcer by the intragastric instillation of acidified ethanol. After $1 \mathrm{~h}$, mice were sacrificed followed by observations on macroscopic and histological damage of the gastric mucosa (Figures 1 and 2).

(A)

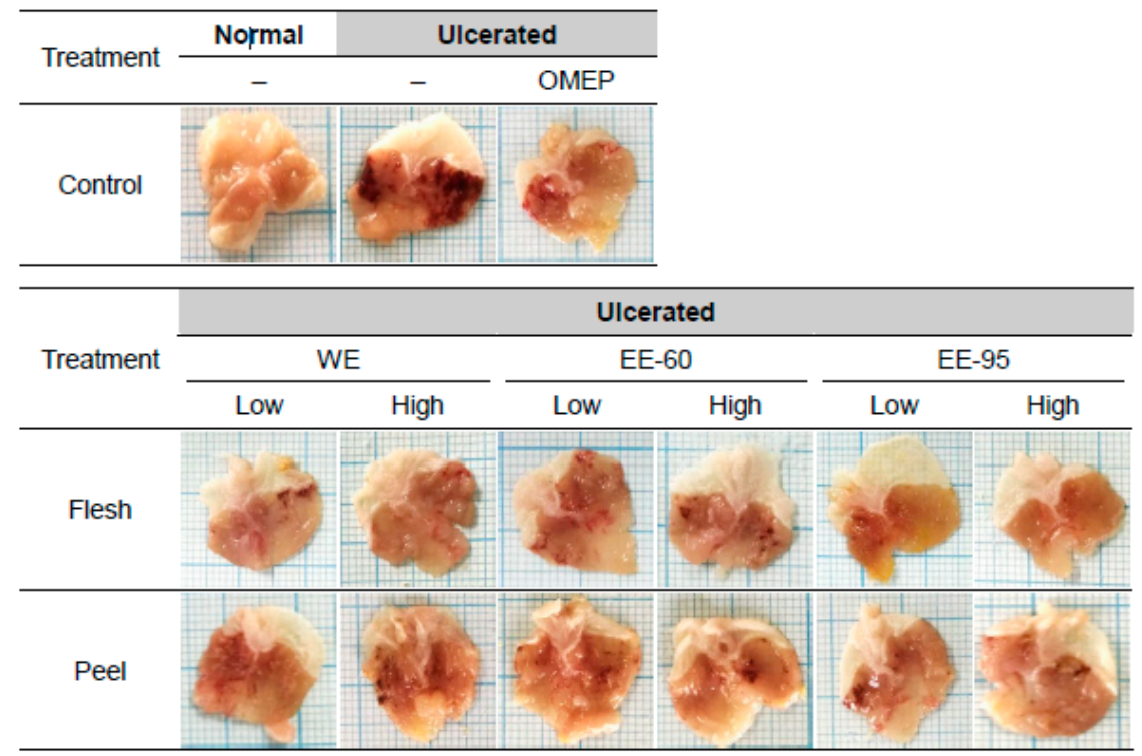

(B)

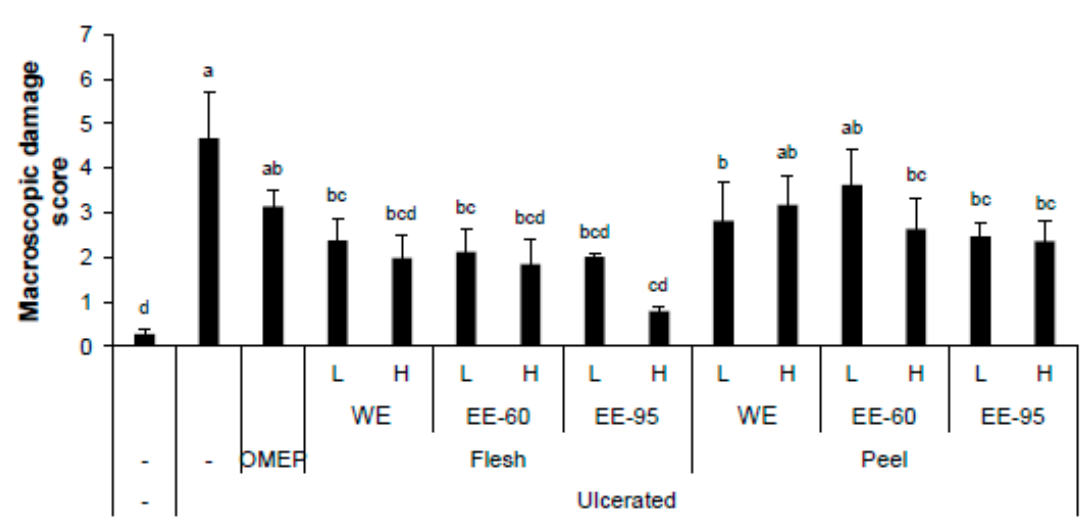

Figure 1. Dioscorea batatas Decne (DBD) flesh and peel extracts improved the macroscopic morphology of gastric damage induced by $\mathrm{HCl}$ /ethanol in mice. ICR mice were randomly assigned to 15 different groups ( 8 mice per group). The water or ethanol extracts of flesh or peel were orally and singly administered, at a designated dose, $3 \mathrm{~h}$ prior to an intragastric infusion of ethanol, to induce acute gastric ulceration. After $1 \mathrm{~h}$, mice were sacrificed. (A) Representative photos of the dissected stomach. (B) Score for macroscopic gastric damage. The data obtained from individual animal samples per group were averaged $(n=8)$; values represent mean \pm standard deviation $(\mathrm{SD})$. OMEP, omeprazole used as a positive control. WE, water extract; EE-60, ethanol extract in 60\% ethanol; EE-95, ethanol extract in $95 \%$ ethanol. Bars not sharing common letter represent statistically significant difference from each other $(p<0.05)$. 
(A)

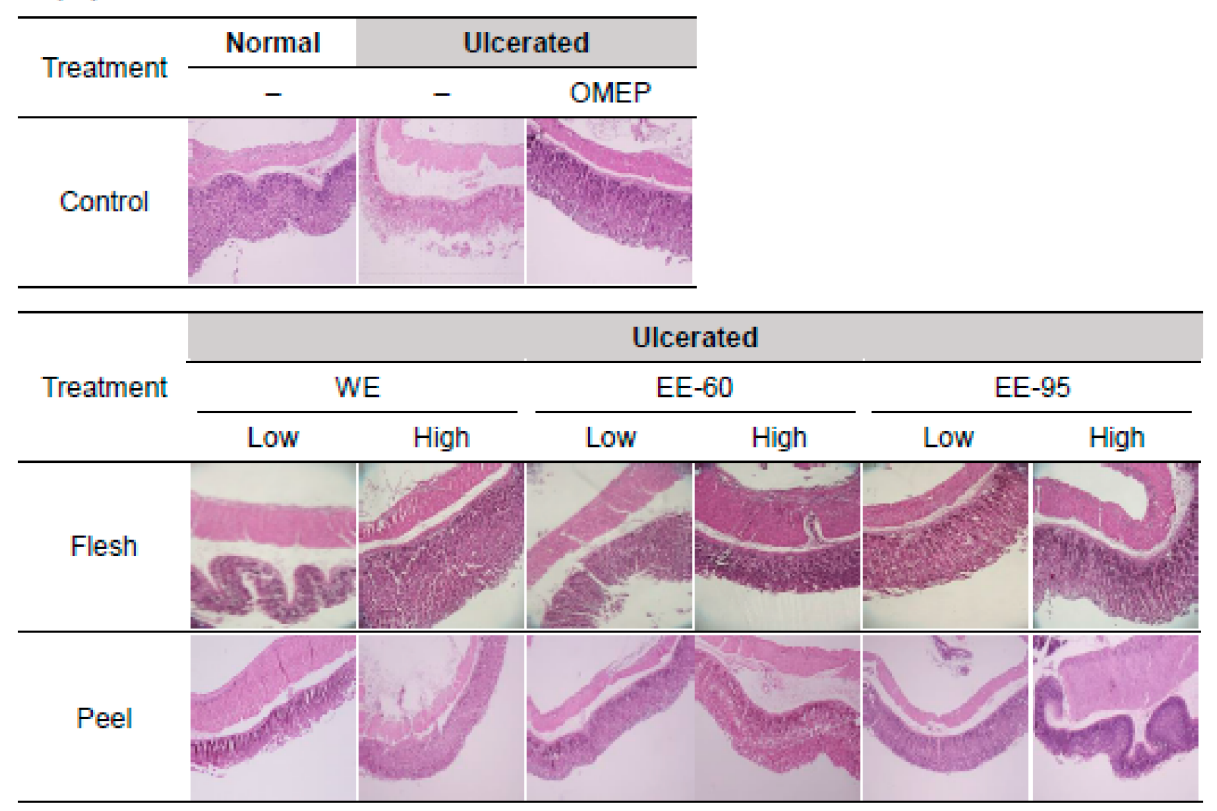

(B)

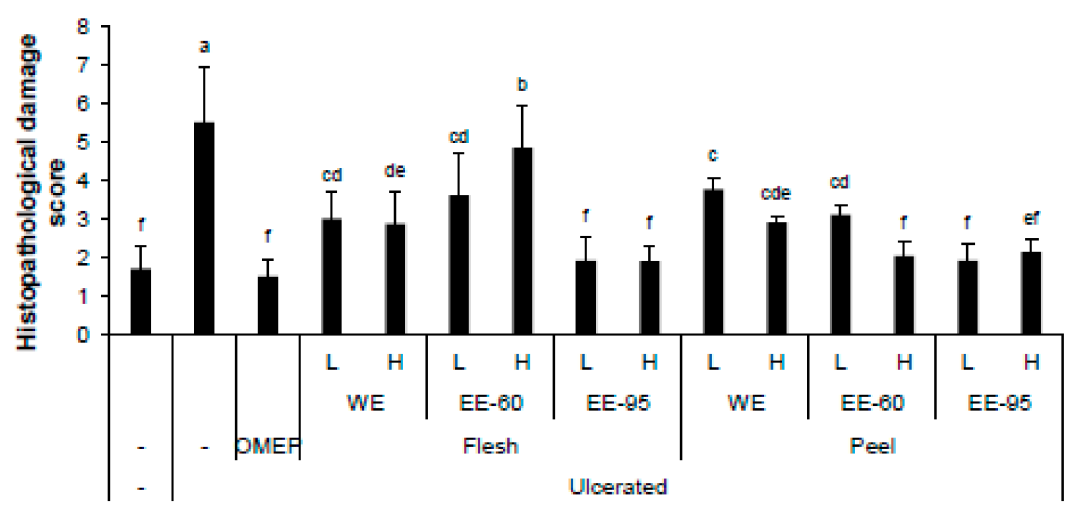

Figure 2. DBD flesh and peel extracts alleviated $\mathrm{HCl}$ /ethanol-induced gastric epithelial damage. The dissected stomach tissue was fixed in formalin solution, embedded in paraffin, sectioned using a microtome, and stained with hematoxylin and eosin (H\&E) for histological analysis. (A) Representative photomicrographs of gastric mucosal surface (magnification, 40×). (B) Score for gastric mucosal damage. Values represent mean $\pm \mathrm{SD}(n=8)$. OMEP, omeprazole used as a positive control. WE, water extract; EE-60, ethanol extract in 60\% ethanol; EE-95, ethanol extract in $95 \%$ ethanol. Bars not sharing common letter represent statistically significant difference from each other $(p<0.05)$.

Acidified ethanol, as expected, induced a large area of hemorrhagic ulcerative gastric lesions (Figure 1A). The severity of the damage was significantly decreased in mice pretreated with both water and ethanol extracts of DBD flesh as well as in mice pretreated with ethanol extract of DBD peel (Figure 1B). Furthermore, ethanol administration caused significant alteration in the gastric epithelium, reflecting hemorrhagic necrosis and collapse of the gastric mucosa with epithelial cell loss (Figure 2A). The pretreatment with DBD flesh and peel extracts significantly alleviated ethanol-induced epithelial damage and contributed to preserving the structure of gastric wall, as evidenced by the low histopathology score (Figure 2B). These macroscopic and histological examinations indicate that both water and ethanol extracts of DBD flesh or peel ameliorated ethanol-induced gastric mucosal damage. 


\subsection{DBD Flesh and Peel Extracts Reduced Acidified Ethanol-Induced Oxidative Stress}

Since the gastric injury caused by ethanol is typically accompanied with oxidative stress in the gastric tissues [25], we examined the levels of biomarkers of oxidative stress, including 8-OHdG (a marker of oxidative DNA damage) in the serum and MDA (an end-product of lipid peroxidation) in the gastric homogenates (Figure 3). The plasma 8-OHdG and gastric MDA concentrations were significantly elevated by ethanol administration (Figure 3A,B), while pretreatment with both water and ethanol extracts of DBD flesh or peel suppressed the elevation of these biomarkers. These findings suggest that water and ethanol extracts of DBD flesh or peel may attenuate the oxidative stress induced by acidified ethanol in the mouse model of acute gastric ulcer.

(A)

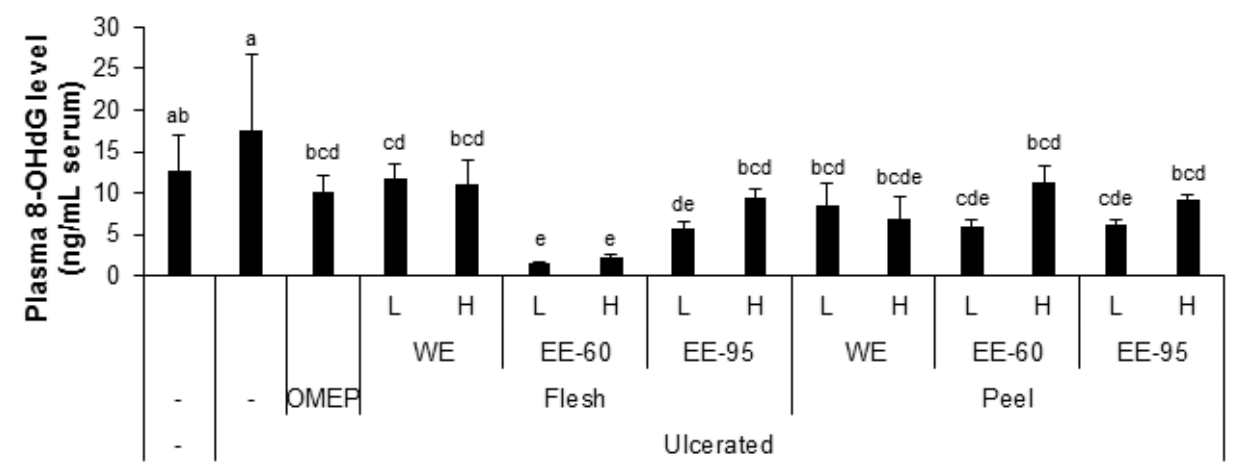

(B)

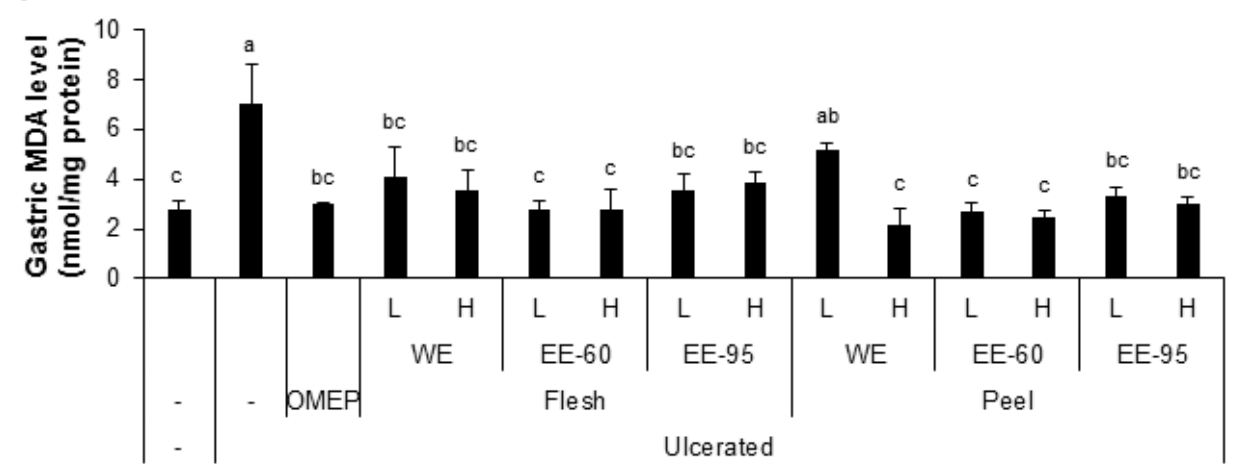

Figure 3. DBD flesh and peel extracts reduced $\mathrm{HCl}$ /ethanol-induced oxidative stress. The levels of 8-OHdG in the serum (A) and malondialdehyde (MDA) in the stomach homogenate (B) were elevated by ulcer induction and lowered by pretreatment with the extracts. Values represent mean $\pm \operatorname{SD}(n=8)$. Bars not sharing common letter represent statistically significant difference from each other $(p<0.05)$.

However, these extracts somewhat, but insignificantly, recovered the activities of antioxidant enzymes, such as CAT and SOD in the serum, that were decreased by ulcer induction by ethanol instillation (Figure 4A,B). Notably, pretreatment with the extract in 60\% ethanol (EE-60) of DBD flesh resulted in a remarkable reduction in $8-\mathrm{OHdG}$ level, and a complete recovery of SOD activity, despite ulcer induction. 
(A)

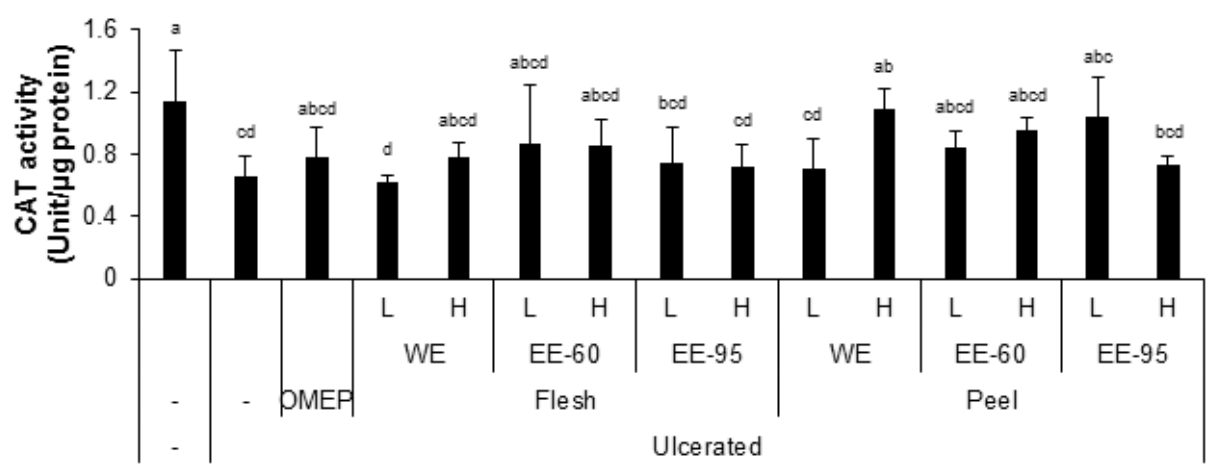

(B)

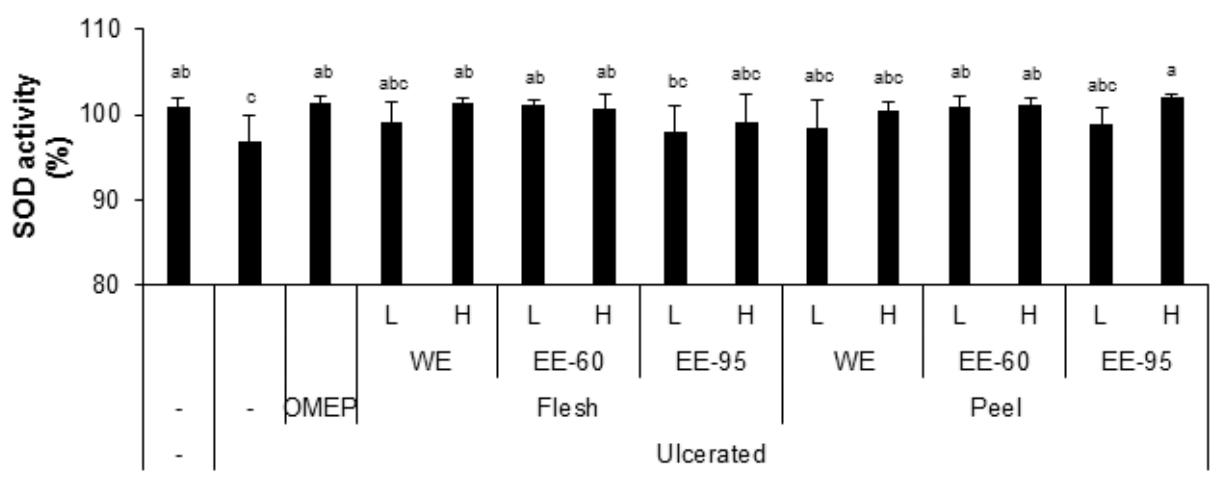

Figure 4. Effect of pretreatment with DBD flesh and peel extracts on catalase (CAT) and superoxide dismutase (SOD) activities in stomach homogenate. $(\mathbf{A}, \mathbf{B}) \mathrm{HCl}$ /ethanol treatment resulted in significant reduction in the activities CAT and SOD. Pretreatment with WE or EE restored the enzyme activities, but not significantly at the 0.05 level. Values represent mean $\pm \mathrm{SD}(n=8)$. Bars not sharing common letter represent statistically significant difference from each other $(p<0.05)$.

\subsection{DBD Flesh and Peel Extracts Decreased Acidified Ethanol-Enhanced Production of Inflammatory Factors}

Although recent studies have highlighted the anti-inflammatory effect of Dioscorea spp., the mechanism underlying the protective effect against ethanol-induced damage is incompletely understood [26-28]. We examined the anti-inflammatory activity of DBD extracts in acute gastric ulcer in mice by evaluating the plasma levels of NO, IL-6, and TNF $\alpha$ (Figure 5). Both water and ethanol extracts of DBD flesh or peel decreased the concentrations of inflammatory factors, including $\mathrm{NO}$ and IL-6, in the serum (Figure 5A,B). In addition, the plasma TNF $\alpha$ level, enhanced by ulceration, was significantly decreased by pretreatment with ethanol extracts of flesh or peel, but not with their water extracts (Figure 5C). 
(A)

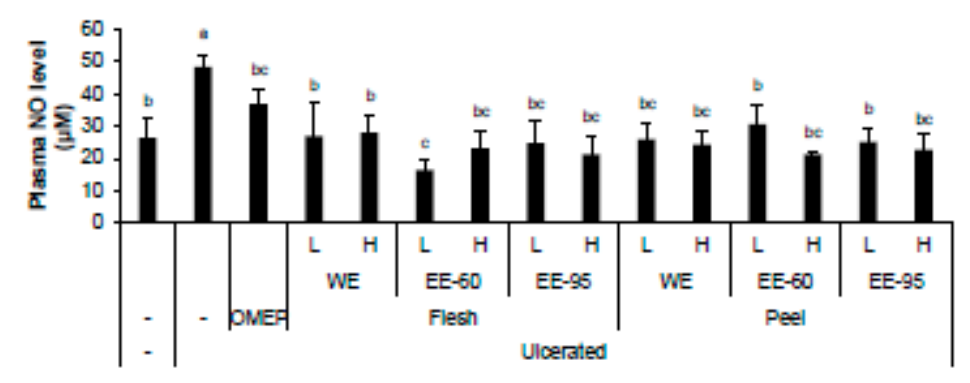

(B)

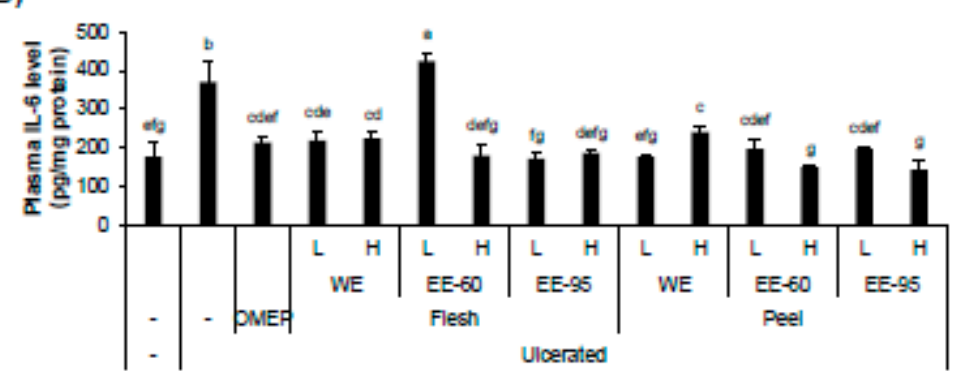

(C)

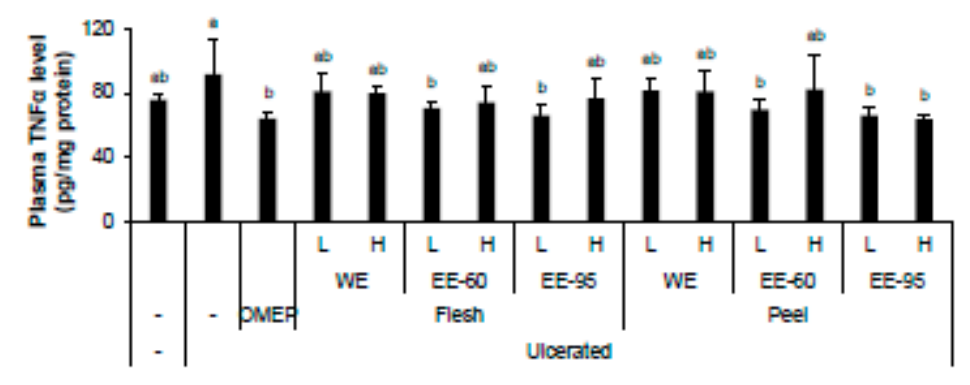

Figure 5. DBD flesh and peel extracts decreased $\mathrm{HCl}$ /ethanol-induced production of inflammatory factors. The serum samples were collected after sacrificing $\mathrm{HCl}$ /ethanol-treated mice. The plasma levels of NO and proinflammatory cytokines (IL- 6 and TNF $\alpha$ ) were measured by ELISAs. The increased levels of plasma NO (A) and IL-6 (B) by gastric ulcer induction were significantly decreased by pretreatment with both WE and EE. However, TNF $\alpha$ levels (C) in the experimental groups were considerably reduced by pretreatment with flesh or peel EE, but not with $\mathrm{WE}$. Values represent mean $\pm \mathrm{SD}(n=8)$. Bars not sharing common letter represent statistically significant difference from each other $(p<0.05)$.

\subsection{DBD Flesh and Peel Extracts Influenced the Expressions of an Inflammatory Marker COX-2 and an} Antioxidant Enzyme HO-1 in Gastric Mucosa

The expression level of COX-2 in the stomach tissue was obviously increased by ethanol administration and significantly reduced by pretreatment with ethanol extracts of DBD fresh or peel (Figure 6A). On the other hand, the expression level of an antioxidant enzyme HO-1 was little influenced by intragastric ethanol instillation, but remarkably increased by pretreatment with ethanol extracts of DBD flesh (Figure 6B). Interestingly, the ethanol extract of DBD peel which was effective in lowering the acidified ethanol-enhanced COX-2 expression, had no significant effect on the expression of HO-1. These observations suggest that the flesh and peel extracts of DBD exert their anti-inflammatory effects through distinct pathways. 
(A)

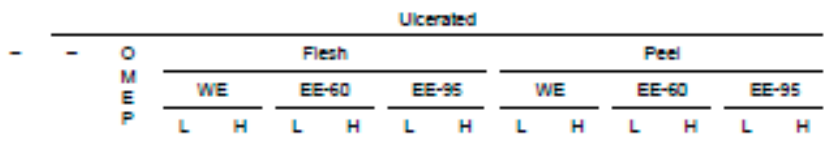
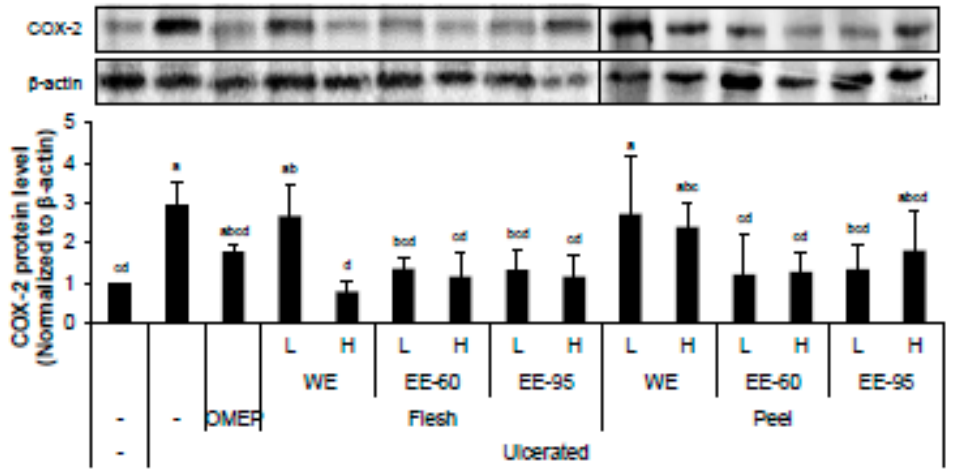

(B)
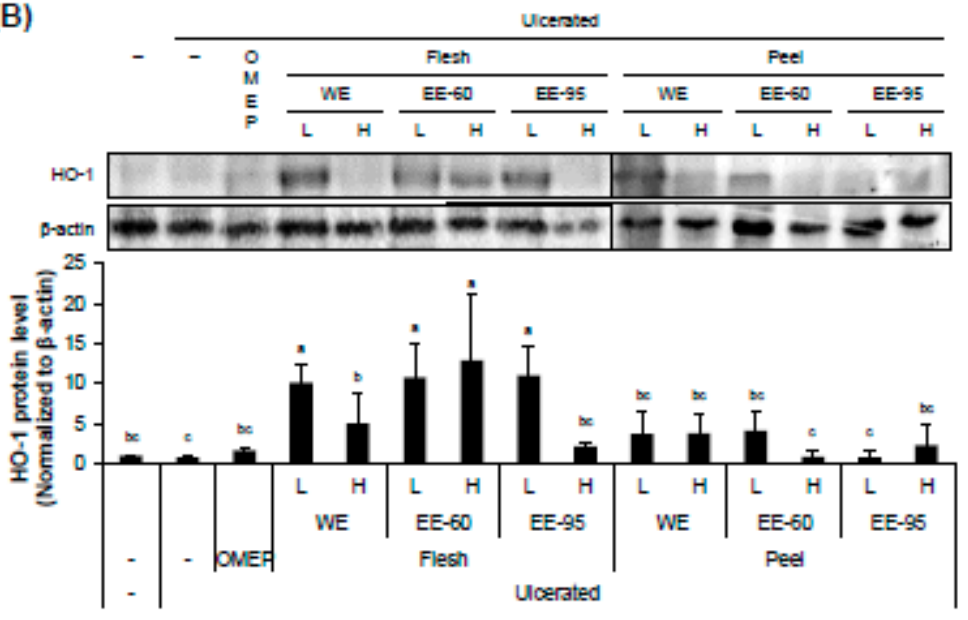

Figure 6. DBD flesh and peel extracts influenced the expressions of the inflammatory marker COX-2 and the antioxidant enzyme HO-1 in gastric mucosa. Stomach homogenates were used for the analysis of protein expression of COX-2 (A) and HO-1 (B). Both WE and EE of flesh and EE of peel reduced the increased expression of $\mathrm{COX}-2$ in $\mathrm{HCl}$ /ethanol-treated stomach. However, $\mathrm{HO}-1$ protein level increased only by pretreatment with flesh extracts; in particular, EE was more potent than WE. Peel extracts showed no significant influence on HO-1 expression. Values represent mean $\pm \mathrm{SD}(n=8)$. Bars not sharing common letter represent statistically significant difference from each other $(p<0.05)$.

\subsection{DBD Flesh and Peel Extracts Increased Acidified Ethanol-Lowered Level of PGE $E_{2}$ in Stomach Homogenate}

$\mathrm{PGE}_{2}$ is known to be endogenously produced in the gastrointestinal mucosa and play a critical role in the healing of gastric ulcer, which is likely to be mediated by EP4 receptor [29]. The level of $\mathrm{PGE}_{2}$ in stomach homogenate was reduced when ulcerated by acidified ethanol; however, pretreatment with the water extract of flesh or the ethanol extract of peel restored the levels of $\mathrm{PGE}_{2}$ (Figure 7). 


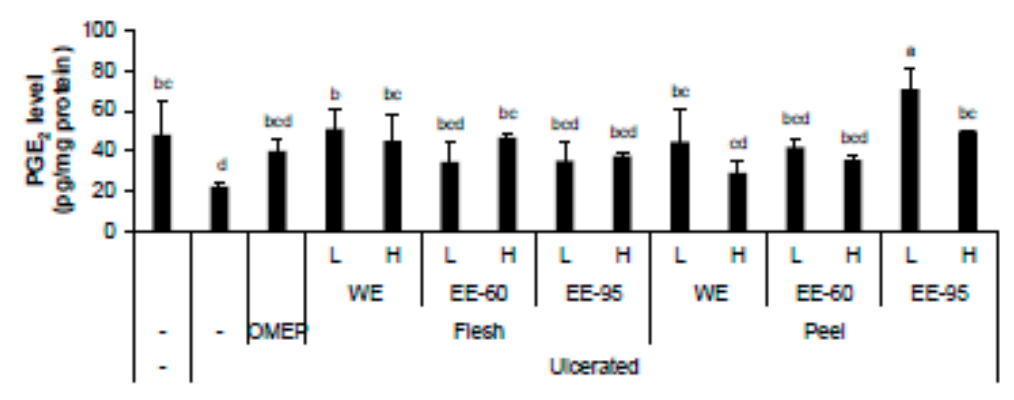

Figure 7. DBD flesh and peel extracts increased the $\mathrm{HCl}$ /ethanol-lowered level of $\mathrm{PGE}_{2}$ level in stomach homogenate. The gastric $\mathrm{PGE}_{2}$ level was prominently decreased by ulcer induction, but the oral administration of the extracts resulted in changes in $\mathrm{PGE}_{2}$ level. In particular, pretreatment with flesh WE and peel EE-95 significantly restored $\mathrm{PGE}_{2}$ level. Values represent mean $\pm \mathrm{SD}(n=8)$. Bars not sharing common letter represent statistically significant difference from each other $(p<0.05)$.

\section{Discussion}

Dioscorea species, belonging to the family Dioscoreaceae, are mostly grown for their starchy tubers or medicinal properties $[26,28,30]$. DBD is known to have biologically beneficial effects including antioxidative, antidiabetic, anti-atherosclerotic, and anti-inflammatory activities [14,16,17,27,31,32]. In particular, the ethanol extract of DBD peel is known to inhibit the production of $\mathrm{NO}$ and $\mathrm{PGE}_{2}$ in lipopolysaccharide-induced Raw 264.7 cells [16]. Supplementation of DBD flesh powder in diet enhanced antioxidant enzyme activities and reduced colonic mucosal inflammatory mediator gene expression in azoxymethane-treated F344 rats [27]. Despite the evidences demonstrating the diverse health-promoting benefits of DBD, little is known about the positive effect of its flesh and peel on gastric injury.

In order to examine the gastroprotective effect of dietary intake of DBD flesh or peel extracts, acute gastric ulcer was induced in adult male ICR mice by intragastric infusion of acidified ethanol with or without DBD pretreatment. Acidified ethanol administration causes acute hemorrhagic gastric damage attributed to increased neutrophil infiltration, which is the sign of inflammatory reaction [33-35]. Omeprazole, an anti-ulcer agent, was used as a positive control, given its popular prescription for the treatment of gastric ulcer [36,37].

The present study demonstrated that oral supplementation with both water and ethanol extracts of DBD flesh and peel protected the mouse gastric mucosa against acidified ethanol-induced injury by decreasing the levels of inflammatory factors, including NO and IL-6 in the serum and COX-2 expression in the gastric tissue, and by increasing the production of gastric $\mathrm{PGE}_{2}$. In particular, the flesh extract prepared in $60 \%$ ethanol significantly restored the gastric $\mathrm{HO}-1$ protein expression and SOD enzyme activity, and reduced oxidative stress biomarkers (plasma 8-OHdG and gastric MDA levels), indicative of the increase in the antioxidative capacity. These findings suggest that the ethanol extract of DBD flesh may exert gastroprotective effects through anti-inflammatory and antioxidative mechanisms accompanied with the upregulation of gastroprotective factor $\mathrm{PGE}_{2}$ production in the gastric mucosa [38].

$\mathrm{PGE}_{2}$ is known to stimulate the secretion of gastric mucus, elevate mucosal blood flow, protect mucosal cells from apoptosis, and accelerate epithelial wound repair and mucosal healing through the activation of prostaglandin E receptors $[29,39]$. Ethanol administration reduces the gastric mucosal $\mathrm{PGE}_{2}$ content [40]. Consistent with the observations reported in the previous studies, our results also demonstrated that $\mathrm{PGE}_{2}$ protein content decreased in stomach homogenate by ethanol infusion. However, pretreatment with water or ethanol extracts of either DBD flesh or peel significantly recovered the $\mathrm{PGE}_{2}$ level, indicating that the gastroprotective effect of the DBD extract was, at least in part, mediated via $\mathrm{PGE}_{2}$.

Multiple studies have identified several compounds obtained from DBD or its derivatives (tuberous root, bark, or fermentates) with pharmacologically potent activities [30]. Considering 
the previous reports on certain bioactive components found in the whole tuber of DBD, such as glycoproteins in water extracts [41] or 6-hydroxy-2,7-dimethoxy-1,4-phenanthraquinone in methanol extract [42], the anti-inflammatory activities of the DBD extract, are presumed to be associated with these components. However, further study is necessary to identify the substances in the DBD extracts responsible for the gastroprotective effect from ethanol-induced ulcers.

Taken together, our findings demonstrate that oral supplementation with the DBD extract, especially ethanol extract of flesh, prior to acidified ethanol administration, may effectively attenuate inflammatory response and enhance antioxidant activities in gastric mucosa and, thereby, alleviating the severity of gastric ulcer.

Author Contributions: J.O. and J.-S.K. conceived and designed the experiments. S.B., J.O. and J.S.L. (Ji Sun Lim) performed the experiments, collected and analyzed the data. S.B., J.O., J.S.L. (Jung Soon Lee) and J.-S.K. interpreted and discussed the data. J.S.L. (Jung Soon Lee) financially supported. J.O. and J.-S.K. wrote the manuscript. All authors read and approved the final version of the manuscript.

Acknowledgments: This study was funded by the Forest Resources Development Institute of Gyeongsangbuk-do, Andong, South Korea (2018).

Conflicts of Interest: The authors declare no conflict of interest.

\section{References}

1. Zabaleta, J. Multifactorial etiology of gastric cancer. Methods Mol. Biol. 2012, 863, 411-435. [PubMed]

2. Cho, C.H.; Koo, M.W.; Garg, G.P.; Ogle, C.W. Stress-induced gastric ulceration: Its aetiology and clinical implications. Scand. J. Gastroenterol. 1992, 27, 257-262. [CrossRef] [PubMed]

3. Tytgat, G.N. Etiopathogenetic principles and peptic ulcer disease classification. Dig. Dis. 2011, $29,454-458$. [CrossRef] [PubMed]

4. Szelenyi, I.; Brune, K. Possible role of oxygen free radicals in ethanol-induced gastric mucosal damage in rats. Dig. Dis. Sci. 1988, 33, 865-871. [CrossRef] [PubMed]

5. Oates, P.J.; Hakkinen, J.P. Studies on the mechanism of ethanol-induced gastric damage in rats. Gastroenterology 1988, 94, 10-21. [CrossRef]

6. Chang, X.; Luo, F.; Jiang, W.; Zhu, L.; Gao, J.; He, H.; Wei, T.; Gong, S.; Yan, T. Protective activity of salidroside against ethanol-induced gastric ulcer via the MAPK/NF-kappaB pathway in vivo and in vitro. Int. Immunopharmacol. 2015, 28, 604-615. [CrossRef] [PubMed]

7. Arab, H.H.; Salama, S.A.; Omar, H.A.; Arafa el, S.A.; Maghrabi, I.A. Diosmin protects against ethanol-induced gastric injury in rats: Novel anti-ulcer actions. PLoS ONE 2015, 10, e0122417. [CrossRef] [PubMed]

8. Asnaashari, S.; Dastmalchi, S.; Javadzadeh, Y. Gastroprotective effects of herbal medicines (roots). Int. J. Food Prop. 2018, 21, 901-919. [CrossRef]

9. Rozza, A.L.; Pellizzon, C.H. Essential oils from medicinal and aromatic plants: A review of the gastroprotective and ulcer-healing activities. Fundam. Clin. Pharmacol. 2013, 27, 51-63. [CrossRef] [PubMed]

10. Awaad, A.S.; El-Meligy, R.M.; Soliman, G.A. Natural products in treatment of ulcerative colitis and peptic ulcer. J. Saudi Chem. Soc. 2013, 17, 101-124. [CrossRef]

11. Geronikaki, A.A.; Gavalas, A.M. Antioxidants and inflammatory disease: Synthetic and natural antioxidants with anti-inflammatory activity. Comb. Chem. High Throughput Screen. 2006, 9, 425-442. [CrossRef] [PubMed]

12. Zhang, H.; Tsao, R. Dietary polyphenols, oxidative stress and antioxidant and anti-inflammatory effects. Curr. Opin. Food Sci. 2016, 8, 33-42. [CrossRef]

13. Wang, L.S.; Tu, Y.C.; Lian, T.W.; Hung, J.T.; Yen, J.H.; Wu, M.J. Distinctive antioxidant and antiinflammatory effects of flavonols. J. Agric. Food Chem. 2006, 54, 9798-9804. [CrossRef] [PubMed]

14. Hou, W.C.; Lee, M.H.; Chen, H.J.; Liang, W.L.; Han, C.H.; Liu, Y.W.; Lin, Y.H. Antioxidant activities of dioscorin, the storage protein of yam (Dioscorea batatas Deene) tuber. J. Agric. Food Chem. 2001, 49, 4956-4960. [CrossRef] [PubMed]

15. Jeon, J.R.; Lee, J.S.; Lee, C.H.; Kim, J.Y.; Kim, S.D.; Nam, D.H. Effect of ethanol extract of dried Chinese yam (Dioscorea batatas) flour containing dioscin on gastrointestinal function in rat model. Arch. Pharm. Res. 2006, 29, 348-353. [CrossRef] [PubMed] 
16. Jin, M.; Suh, S.J.; Yang, J.H.; Lu, Y.; Kim, S.J.; Kwon, S.; Jo, T.H.; Kim, J.W.; Park, Y.I.; Ahn, G.W.; et al. Anti-inflammatory activity of bark of Dioscorea batatas DECNE through the inhibition of iNOS and COX-2 expressions in RAW264.7 cells via NF-kappa B and ERK1/2 inactivation. Food Chem. Toxicol. 2010, 48, 3073-3079. [CrossRef] [PubMed]

17. Hou, W.C.; Hsu, F.L.; Lee, M.H. Yam (Dioscorea batatas) tuber mucilage exhibited antioxidant activities in vitro. Planta Med. 2002, 68, 1072-1076. [CrossRef] [PubMed]

18. Xu, T.; Zheng, L.; Xu, L.; Yin, L.; Qi, Y.; Xu, Y.; Han, X.; Peng, J. Protective effects of dioscin against alcohol-induced liver injury. Arch. Toxicol. 2014, 88, 739-753. [CrossRef] [PubMed]

19. Zakarova, A.; Seo, J.Y.; Kim, H.Y.; Kim, J.H.; Shin, J.H.; Cho, K.M.; Lee, C.H.; Kim, J.S. Garlic Sprouting Is Associated with Increased Antioxidant Activity and Concomitant Changes in the Metabolite Profile. J. Agric. Food Chem. 2014, 62, 1875-1880. [CrossRef] [PubMed]

20. Tabuchi, Y.; Sugiyama, N.; Horiuchi, T.; Furusawa, M.; Furuhama, K. Ebselen, a seleno-organic compound, protects against ethanol-induced murine gastric mucosal injury in both in vivo and in vitro systems. Eur. J. Pharmacol. 1995, 272, 195-201. [CrossRef]

21. Biswas, K.; Bandyopadhyay, U.; Chattopadhyay, I.; Varadaraj, A.; Ali, E.; Banerjee, R.K. A novel antioxidant and antiapoptotic role of omeprazole to block gastric ulcer through scavenging of hydroxyl radical. J. Biol. Chem. 2003, 278, 10993-11001. [CrossRef] [PubMed]

22. Seo, H.; Oh, J.; Hahn, D.; Kwon, C.S.; Lee, J.S.; Kim, J.S. Protective Effect of Glyceollins in a Mouse Model of Dextran Sulfate Sodium-Induced Colitis. J. Med. Food 2017, 20, 1055-1062. [CrossRef] [PubMed]

23. Bito, T.; Misaki, T.; Yabuta, Y.; Ishikawa, T.; Kawano, T.; Watanabe, F. Vitamin B12 deficiency results in severe oxidative stress, leading to memory retention impairment in Caenorhabditis elegans. Redox. Biol. 2017, 11, 21-29. [CrossRef] [PubMed]

24. Holcik, M.; Gordon, B.W.; Korneluk, R.G. The internal ribosome entry site-mediated translation of antiapoptotic protein XIAP is modulated by the heterogeneous nuclear ribonucleoproteins C1 and C2. Mol. Cell. Biol. 2003, 23, 280-288. [CrossRef] [PubMed]

25. Franke, A.; Teyssen, S.; Singer, M.V. Alcohol-related diseases of the esophagus and stomach. Dig. Dis. 2005, 23, 204-213. [CrossRef] [PubMed]

26. Kumar, S.; Das, G.; Shin, H.S.; Patra, J.K. Dioscorea spp. (A Wild Edible Tuber): A Study on Its Ethnopharmacological Potential and Traditional Use by the Local People of Similipal Biosphere Reserve, India. Front. Pharmacol. 2017, 8, 52. [CrossRef] [PubMed]

27. Son, I.S.; Lee, J.S.; Lee, J.Y.; Kwon, C.S. Antioxidant and Anti-inflammatory Effects of Yam (Dioscorea batatas Decne.) on Azoxymethane-induced Colonic Aberrant Crypt Foci in F344 Rats. Prev. Nutr. Food Sci. 2014, 19, 82-88. [CrossRef] [PubMed]

28. Dey, P.; Roy Chowdhuri, S.; Sarkar, M.P.; Chaudhuri, T.K. Evaluation of anti-inflammatory activity and standardisation of hydro-methanol extract of underground tuber of Dioscorea alata. Pharm. Biol. 2016, 54, 1474-1482. [CrossRef] [PubMed]

29. Wallace, J.L. Prostaglandins, NSAIDs, and gastric mucosal protection: Why doesn't the stomach digest itself? Physiol. Rev. 2008, 88, 1547-1565. [CrossRef] [PubMed]

30. Lu, Y.L.; Chia, C.Y.; Liu, Y.W.; Hou, W.C. Biological activities and applications of dioscorins, the major tuber storage proteins of yam. J. Tradit. Complement. Med. 2012, 2, 41-46. [CrossRef]

31. Go, H.K.; Rahman, M.M.; Kim, G.B.; Na, C.S.; Song, C.H.; Kim, J.S.; Kim, S.J.; Kang, H.S. Antidiabetic Effects of Yam (Dioscorea batatas) and Its Active Constituent, Allantoin, in a Rat Model of Streptozotocin-Induced Diabetes. Nutrients 2015, 7, 8532-8544. [CrossRef] [PubMed]

32. Koo, H.J.; Park, H.J.; Byeon, H.E.; Kwak, J.H.; Um, S.H.; Kwon, S.T.; Rhee, D.K.; Pyo, S. Chinese yam extracts containing beta-sitosterol and ethyl linoleate protect against atherosclerosis in apolipoprotein E-deficient mice and inhibit muscular expression of VCAM-1 in vitro. J. Food Sci. 2014, 79, H719-H729. [CrossRef] [PubMed]

33. Li, W.; Huang, H.; Niu, X.; Fan, T.; Mu, Q.; Li, H. Protective effect of tetrahydrocoptisine against ethanol-induced gastric ulcer in mice. Toxicol. Appl. Pharmacol. 2013, 272, 21-29. [CrossRef] [PubMed]

34. Yoo, J.H.; Lee, J.S.; Lee, Y.S.; Ku, S.; Lee, H.J. Protective effect of bovine milk against $\mathrm{HCl}$ and ethanol-induced gastric ulcer in mice. J. Dairy Sci. 2018, 101, 3758-3770. [CrossRef] [PubMed]

35. Li, W.F.; Hao, D.J.; Fan, T.; Huang, H.M.; Yao, H.; Niu, X.F. Protective effect of chelerythrine against ethanol-induced gastric ulcer in mice. Chem. Biol. Interact. 2014, 208, 18-27. [CrossRef] [PubMed] 
36. Kedika, R.R.; Souza, R.F.; Spechler, S.J. Potential anti-inflammatory effects of proton pump inhibitors: A review and discussion of the clinical implications. Dig. Dis. Sci. 2009, 54, 2312-2317. [CrossRef] [PubMed]

37. El-Nezhawy, A.O.; Biuomy, A.R.; Hassan, F.S.; Ismaiel, A.K.; Omar, H.A. Design, synthesis and pharmacological evaluation of omeprazole-like agents with anti-inflammatory activity. Bioorg. Med. Chem. 2013, 21, 1661-1670. [CrossRef] [PubMed]

38. Laine, L.; Takeuchi, K.; Tarnawski, A. Gastric mucosal defense and cytoprotection: Bench to bedside. Gastroenterology 2008, 135, 41-60. [CrossRef] [PubMed]

39. Takeuchi, K.; Amagase, K. Roles of Cyclooxygenase, Prostaglandin E2 and EP Receptors in Mucosal Protection and Ulcer Healing in the Gastrointestinal Tract. Curr. Pharm. Des. 2018, 24, 2002-2011. [CrossRef] [PubMed]

40. Zhao, W.; Zhu, F.; Shen, W.; Fu, A.; Zheng, L.; Yan, Z.; Zhao, L.; Fu, G. Protective effects of DIDS against ethanol-induced gastric mucosal injury in rats. Acta Biochim. Biophys. Sin. (Shanghai) 2009, 41, 301-308. [CrossRef] [PubMed]

41. Lee, S.J.; Lim, K.T. Inhibitory effect of 30-kDa phytoglycoprotein on expression of TNF-alpha and COX-2 via activation of PKCalpha and ERK 1/2 in LPS-stimulated RAW 264.7 cells. Mol. Cell. Biochem. 2008, 317, 151-159. [CrossRef] [PubMed]

42. Jin, M.H.; Lu, Y.; Yang, J.H.; Jo, T.H.; Park, Y.I.; Lee, C.K.; Park, S.J.; Son, K.H.; Chang, H.W. Anti-inflammatory Activity of 6-Hydroxy-2,7-dimethoxy-1,4-henanthraquinone from Tuberous Roots of Yam (Dioscorea batatas) through Inhibition of Prostaglandin D-2 and Leukotriene C-4 Production in Mouse Bone Marrow-derived Mast Cells. Arch. Pharm. Res. 2011, 34, 1495-1501. [CrossRef] [PubMed]

(C) 2018 by the authors. Licensee MDPI, Basel, Switzerland. This article is an open access article distributed under the terms and conditions of the Creative Commons Attribution (CC BY) license (http://creativecommons.org/licenses/by/4.0/). 